\title{
Impact of Mahatma Gandhi National Rural Employment Guarantee Scheme (MGNREGS) on Paddy Cultivation in Palakkad District of Kerala
}

\author{
S. Lakshmi ${ }^{1}$ and M.Sundaramari ${ }^{2}$
}

\begin{abstract}
The study was undertaken to assess the impact of Mahatma Gandhi National Rural Employment Guarantee Scheme (MGNREGS) on paddy cultivation and the constraints faced by the farmers due to the implementation of this scheme in Palakkad district of Kerala. A sample of 120 paddy farmers from Kuzhalmannom Block was randomly selected for the study. The study revealed that the most important impact of the scheme as perceived by the paddy farmers was increase in water availability for irrigation. As for the constraints faced by the paddy farmers due to MGNREGS, increased wage rate of labourers was ranked first followed by non-availability of labourers during peak season and decreased productivity of labour.
\end{abstract}

Keywords: MGNREGS; Impact; Paddy cultivation; Constraints; Kerala

\section{INTRODUCTION}

Mahatma Gandhi National Rural Employment Guarantee Scheme (MGNREGS) is the first country-wide employment scheme that guaranteed employment legally to the rural population of India through an act. The overall aim of the scheme includes extreme poverty eradication and making villages selfsustaining through the creation of productive assets. This is intended to rejuvenate the natural resources in rural areas as well as to provide sustainable livelihood to poor people. In Kerala, the MGNREGS was implemented in three phases. In its first phase, the programme was started in the rural districts of Palakkad and
Wayanad in 2006. It was extended to Idukki and Kasaragod districts as the second phase in 2007 and later expanded to all the districts from April, 2008 onwards in the third phase. The activities under MGNREGS have a direct effect on agriculture production and natural resources. The activities which are directly related to agriculture production includes water conservation and water harvesting, , flood control, land development, micro irrigation works, renovation of traditional water bodies and works on individual's land.

Agriculture sector in Kerala is facing many challenges with respect to growth, even though it has much potential. The Directorate

1. Ph.D Research Scholar and 2. Professor, School of Agriculture \& Animal Sciences, Gandhigram Rural Institute (Deemed to be University), Gandhigram, Tamil Nadu 
Impact of Mahatma Gandhi National Rural Employment Guarantee Scheme (MGNREGS) on Paddy Cultivation in Palakkad District of Kerala

of Economics and Statistics, Government of Kerala, the agriculture and allied sectors contributed Rs.69,91,199 lakhs, which was 12.75 percent of the total Gross State Value Added (GSVA) in the year 2016-17 at current prices. Paddy is the major food crop of Kerala. The lush green paddy fields are the most characteristic feature of Kerala landscape. The cultivation of paddy is the main agricultural activity in the coastal and midland wet fields of Kerala and is also connected with the culture and festivals of the State.

However, the area under paddy cultivation in the State shows a continuous decline during the last four decades. The area under paddy was 8.82 lakh hectares during
1974-75, which was at its peak, had come down to 1.71 lakh hectares in 2016-17. The area under paddy to gross cropped area had also declined from 33 percent in 1974-75 to 6.63 percent in 2016-17. The area and production of paddy in Palakkad district from 2005-06 to 2016-17 is provided in Figure 1.

The production of rice declined in the State and now it produces only 19 percent of its requirement (Rajasekharan and Anila, 2016). The results showed a wide gap in the consumption and production of food grains especially rice, the staple diet of people in Kerala. Moreover, the decline in area under paddy and the quantity of rice produced in the state has important implications on the state's

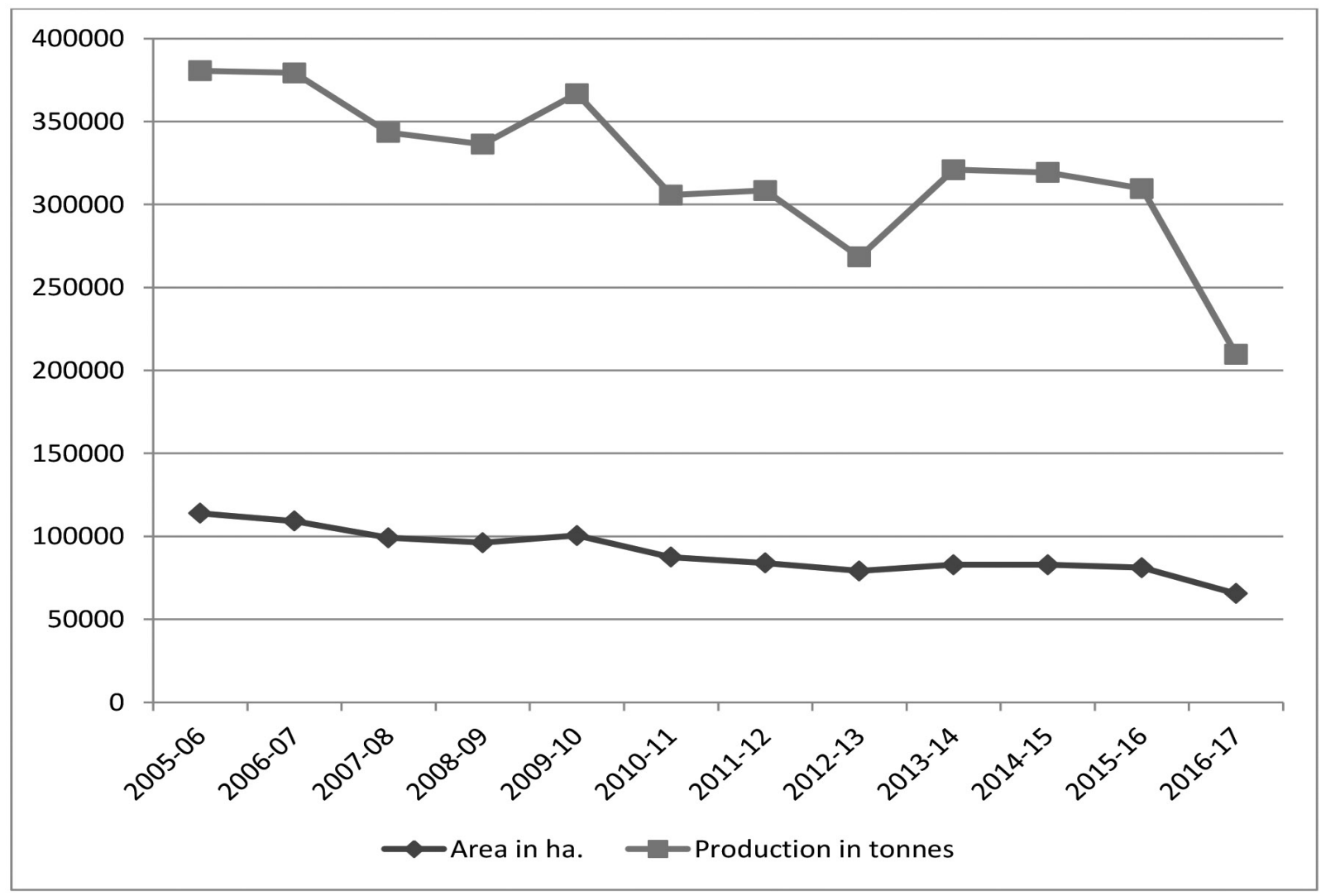

Fig.1. Area and Production of Paddy in Palakkad district 
economic, ecological and social development. The assessment of impact of MGNREGS in Palakkad district of Kerala was conducted with the following objectives:

- To assess the impact of MGNREGS on paddy cultivation

- To identify the constraints faced by the farmers due to MGNREGS

\section{METHODOLOGY}

The study employed both analytical and descriptive methods. The primary data for the study were collected from randomly selected 120 paddy farmers in Kuzhalmannom Block of Palakkad District. Palakkad District and Kuzhalmannom Block were purposively selected for the study. Palakkad district was selected as it is one of the districts in which MGNREGA was implemented during the first phase in the State. Moreover, Palakkad District has been considered as one of the "Rice Bowls" of Kerala. Kuzhalmannom Block was selected as it is having maximum area under paddy cultivation during 2015-16. The secondary data for the study were collected from various reports, journals, research studies, etc.

Based on the review of literature and discussions with farmers and agricultural experts, twenty one statements were found useful for eliciting the perception of farmers about the impact of the scheme on agriculture. These statements were sent to the judges for relevancy rating on a five point continuum i.e. most relevant, relevant, undecided, less relevant and least relevant with the weighages of 5, 4, 3, 2 and 1 respectively. The relevancy weight of 21 statements was calculated by dividing the actual score received for a statement with maximum score possible for a statement. The mean of the relevancy weights of all the 21 statements was worked out and it was 0.82. The statements with relevancy weight lesser than the mean relevancy weight were ignored and thus 10 statements were selected for studying the perceived impact of MGNREGS on paddy cultivation.

The paddy farmers were asked to rate the statements based on their perception about the impact of the scheme on paddy cultivation in a five point continuum viz. strongly agree, agree, neutral, disagree and strongly disagree with scores 5, 4, 3, 2 and 1 respectively. The total weighted score for each of the 10 statements were calculated and based on these scores the statements were ranked from 1 to 10 .

For constraint analysis, the selected constraints were produced in the interview schedule and the respondents were asked whether they had faced such a constraint. A score of '2' was provided for statements which were perceived as a constraint by the farmers and a score of ' 1 ' was provided to the statements which were not considered as a constraint by them. The scores obtained for each constraint based on the perception of farmers were summed up and divided by the total number of respondents to get the severity score of each constraint. Based on the severity scores obtained, the constraints 
Impact of Mahatma Gandhi National Rural Employment Guarantee Scheme (MGNREGS) on Paddy Cultivation in Palakkad District of Kerala

were ranked. Appropriate statistical analysis was used to have a meaningful interpretation.

\section{FINDINGS AND DISCUSSION}

\section{Impact of MGNREGS on Agriculture}

The perception of farmers about the impact of MGNREGS on paddy cultivation was collected and is furnished in Table 1. The responses of the farmers were collected for all ten identified statements in order to assess their perception about the impact of MGNREGS. The most important impact of the scheme as perceived by the farmers was increase in water availability for irrigation followed by reduction in fallow land. As reported by the farmers the availability of labour for agriculture related activities decreased. A discussion on each of the impact as perceived by the farmers is given below.

\section{Increased Water Availability for Irrigation}

Based on the the perception of farmers, the most important impact of MGNREGS was increased water availability for irrigation. As a result of the global phenomenon of climate change, Kerala had experienced decline in annual and monsoon rainfall and increase in temperature for the past few years, till 2018. The ground water table is also found to be depleting at a faster rate than its recharging capacity due to various factors like decline in rainfall, overuse of water for irrigation, deforestation, decline in wet land and disappearance of lakes and ponds. In this context the water conservation and water harvesting works taken up under MGNREGS viz., cleaning and renovation of traditional water bodies, irrigation works and watershed management works, etc., had definitely

Table 1

Impact of MGNREGS on Agriculture

\begin{tabular}{|c|c|c|c|c|c|c|c|c|}
\hline \multirow{2}{*}{$\begin{array}{l}\text { Sl. } \\
\text { No. }\end{array}$} & \multirow{2}{*}{ Impact of MGNREGS on Agriculture } & \multicolumn{5}{|c|}{ Scoring pattern } & \multirow{2}{*}{$\begin{array}{l}\text { Total } \\
\text { Score }\end{array}$} & \multirow{2}{*}{ Rank } \\
\hline & & 5 & 4 & 3 & 2 & 1 & & \\
\hline 1 & Cropping pattern has changed & 40 & 38 & 22 & 16 & 4 & 454 & 4 \\
\hline 2 & Area under cultivation has increased & 8 & 30 & 42 & 32 & 8 & 358 & 8 \\
\hline 3 & $\begin{array}{l}\text { Water availability for irrigation has } \\
\text { increased }\end{array}$ & 58 & 34 & 18 & 8 & 2 & 498 & 1 \\
\hline 4 & $\begin{array}{l}\text { Duration of water availability in a year } \\
\text { has increased }\end{array}$ & 24 & 40 & 36 & 14 & 6 & 422 & 5 \\
\hline 5 & $\begin{array}{l}\text { Access/proximity to irrigation sources } \\
\text { has increased }\end{array}$ & 14 & 40 & 56 & 8 & 2 & 416 & 6 \\
\hline 6 & $\begin{array}{l}\text { Number of irrigation sources has } \\
\text { increased }\end{array}$ & 30 & 60 & 16 & 8 & 6 & 460 & 3 \\
\hline 7 & Reduction in fallow land & 50 & 42 & 20 & 4 & 4 & 490 & 2 \\
\hline
\end{tabular}




\begin{tabular}{|c|l|c|c|c|c|c|c|c|}
\hline \multirow{2}{*}{$\begin{array}{c}\text { SI. } \\
\text { No. }\end{array}$} & Impact of MGNREGS on Agriculture & \multicolumn{5}{|c|}{ Scoring pattern } & Total & \multirow{2}{*}{ Score } \\
\cline { 2 - 9 } & $\mathbf{5}$ & $\mathbf{4}$ & $\mathbf{3}$ & $\mathbf{2}$ & $\mathbf{1}$ & Rank \\
\hline 8 & $\begin{array}{l}\text { NonAvailability of labour for } \\
\text { agriculture related activities has } \\
\text { increased }\end{array}$ & 2 & 10 & 16 & 32 & 60 & 222 & 10 \\
\hline 9 & $\begin{array}{l}\text { Labour expenses for cultivation of } \\
\text { crops has increased }\end{array}$ & 6 & 8 & 18 & 28 & 60 & 232 & 9 \\
\hline 10 & Income from agriculture has increased & 18 & 30 & 40 & 24 & 8 & 386 & 7 \\
\hline
\end{tabular}

helped to increase the water availability for irrigation to a certain extent.

Reduction in Fallow land

The second most important impact of MGNREGS was decline in the extent of fallow land. Reason for this could be attributed to various land development activities carried out under the scheme. Moreover, MGNREGS workers were also associated with various schemes for carrying out cultivation of paddy in fallow lands.

Increased number of Irrigation sources

Increased number of irrigation sources was the third major impact of the scheme as perceived by the farmers. This might be due to the importance provided to different works carried out under water harvesting and conservation activities and renovation of existing water bodies as well as creation of new ponds, canals, etc.

\section{Change in Cropping Pattern}

Change in cropping pattern was reported as the fourth major impact of MGNREGS according to the perception of the sample farmers. It is quite natural that increase in irrigation sources would lead to increased water availability for irrigation. This increased water availability might have encouraged the farmers to have a positive change in cropping pattern in the study area.

\section{Duration of Water Availability and Increased Proximity of Irrigation Sources}

The duration of annual water availability in the area had increased and this was perceived as the fifth impact of the scheme by the farmers. The increased duration of water availability was mainly due to the renovation of existing canals and creation of new water sources and water harvesting structures carried out under the scheme. This had also increased the proximity of irrigation sources, the sixth impact of the scheme according to farmers.

Impact of Income on Agriculture, Area under cultivation, Labour expenses for cultivation of crops and Labour availability

The last four impacts of the scheme were about income from agriculture, area under cultivation, labour expenses for cultivation of crops and availability of labour for agriculture related activities. Almost all the beneficiaries strongly disagreed with the statement that the 
Impact of Mahatma Gandhi National Rural Employment Guarantee Scheme (MGNREGS) on Paddy Cultivation in Palakkad District of Kerala

labour expenses for cultivation of crops had decreased and the availability of labour for agriculture related activities had increased. The labour unavailability during the cultivation season also pointed out that the MGNREGS works were being taken up without considering the agriculture season of the region.

Constraints experienced by the Farmers in Paddy Cultivation due to MGNREGS

The constraints perceived by the paddy farmers in the order of severity are presented in Table 2. The maximum score possible for a constraint was 2 and the minimum score possible was 0 . The farmers identified six constraints that they had experienced as a result of MGNREGS implementation in the region. The most important constraint experienced by them is revealed to be the increase in wage rates of labourers followed by non-availability of labourers during peak season. The last constraint perceived by the farmers as a result of scheme implementation was increase in use of pesticide. A brief discussion on the various constraints faced by the farmers due to MGNREGS is provided below.

\section{Increased Wage Rate of Labourers}

The most important constraint faced by the farmers due to MGNREGS was the increased wage rate of labourers. Almost all the farmers reported that the wage rate of labourers for various activities of paddy cultivation has increased as a result of the scheme. When it was first introduced in all parts of the state, the MGNREGS wages was ₹125/- per day in Kerala as against the national average wage rate of ₹96.26/-. At the same period, the wage rate of an unskilled female farm labour for doing activities like weeding was less than the MGNREGS wage rate. Besides making the female labour force to gravitate towards MGNREGS works, the scheme also increased the bargaining power of the female labour force engaged in agricultural activities. This ultimately ended up in getting their average wage rate in the farms and paddy fields hiked up to a slot even higher than the MGNREGS rate.

\section{Non-availability of Labourers}

Non-availability of labourers during peak season was the second major constraint faced by the paddy farmers. The shifting of

Table 2

Constraints Experienced by the Farmers

\begin{tabular}{|c|l|c|c|}
\hline SI. No. & \multicolumn{1}{|c|}{ Constraints } & Overall Score & Rank \\
\hline 1 & Increased wage rate of labourers & 1.98 & $\mathrm{I}$ \\
\hline 2 & Non-availability of labourers during peak season & 1.89 & $\mathrm{II}$ \\
\hline 3 & Decreased productivity of labour & 1.84 & $\mathrm{III}$ \\
\hline 4 & Increased cost of cultivation & 1.78 & $\mathrm{IV}$ \\
\hline 5 & Increased use of weedicide & 1.47 & $\mathrm{~V}$ \\
\hline 6 & Increase in the use of pesticides & 1.33 & $\mathrm{VI}$ \\
\hline
\end{tabular}


agricultural labourers from agriculture to other occupations also led to the shortage of labourers. The number of persons engaged in agriculture in the state reduced drastically even as the total number of workers increased between 1993-94 and 2012-13.

\section{Decreased Productivity of Labourers}

The third important constraint as perceived by the farmers was the decreased productivity of labourers. The farmers opined that the work done by a labourer before implementing MGNREGS is now done by three labourers. Almost all the sample farmers contacted were of the opinion that besides making the availability of farm labour scarce, MGNREGS had also contributed negatively to the general work culture of the labourers.

\section{Increased Cost of Cultivation}

Increased cost of cultivation was the other major constraint faced by the paddy farmers. The labour cost constitutes more than 50 percent of the total paid out cost, leading to increased cost of cultivation. The cost of all the inputs used had increased many folds as well. This has led to decreased profit from paddy cultivation. Many of the farmers reported that the Minimum Support Price (MSP) for paddy provided by the Government had encouraged them to continue paddy cultivation to some extent.

\section{Increased use of Weedicides and Pesticides}

The other constraints faced by the farmers were increased use of weedicides and pesticides. In paddy farming, weeding is a labour intensive work. Traditionally, women workers are performing the weeding activities. The advent of MGNREGS has resulted in a shortage of labour for these kinds of works. It is also reported from the field that the climate change being experienced at present has contributed to increase in weed population. These two reasons plus the increased labour cost have resulted in an increase in the use of weedicides like roundup in the paddy fields.

\section{CONCLUSION}

The major positive impacts of the scheme as reported by paddy farmers in Palakkad district include increased water availability for irrigation, increased number of water resources and reduction in fallow land. This may be due to the implementation of various activities which were directly related to agriculture production under MGNREGS. Moreover, the district had utilized 17,522.62 lakhs under the scheme for various works supporting agriculture production during 2016-17.

The major constraints faced by the paddy farmers due to MGNREGS were increased wage rate of labourers, nonavailability of labourers during peak season and decreased productivity of labourers. These constraints faced by the farmers had resulted in increased cost of cultivation.

The study revealed that the constraints faced by the paddy farmers were not solely due to the implementation of MGNREGS. The educational level of the younger generation in Kerala is on the higher side when compared to other states and most of them are reluctant to do tedious physical works in the agricultural 
Impact of Mahatma Gandhi National Rural Employment Guarantee Scheme (MGNREGS) on Paddy Cultivation in Palakkad District of Kerala

fields. The uncertainty about the income from agriculture and availability of other jobs with high income has also made people to go away from agriculture. Proper planning of MGNREGS works and effective utilization of MGNREGS workers for agriculture can make it profitable one to a certain extent.

\section{REFERENCES}

Rajasekharan, P. \& Anila, T. (2016). Rice in Kerala -Towards an evolutionary perspective, chapter 6. In Rice in Kerala: Traditions, Technologies and Identities: A life perspective, Kerala State Planning Board. 